\title{
Fractura de cadera en anciano: un gran desafío anestésico. Utilidad de la ecocardiografía transesofágica para su monitorización
}

Max Wanner Espinoza

María Carolina Cabrera

Departamento de Anestesiología. Universidad de Valparaíso. Chile

\section{Correspondencia}

Maria Carolina Cabrera

maria.cabrera@uv.c

Recibido: 05/01/2020

Aceptado: 05/01/2020

En línea: 02/03/2020

Citar como: Wanner-Espinoza M, Cabrera MC. Fractura de cadera en anciano: un gran desafío anestésico. Utilidad de la ecocardiografía transesofágica para su monitorización. Rev Ecocar Pract (RETIC). 2020 (Mar); 3 (1): 60-61. doi: 10.37615/retic.v3n1a16.

Cite this as: Wanner-Espinoza M, Cabrera MC. Hip fracture in the elderly: a great anesthetic challenge. Usefulness of transesophageal echocardiography for monitoring. Rev Ecocar Pract (RETIC). 2020 (Mar); 3 (1): 60-61. doi: 10.37615/retic.v3n1a16.

\begin{tabular}{|c|}
\hline Palabras clave \\
\hline $\begin{array}{l}\triangleright \text { Monitorización anestésica } \\
\triangleright \text { Ecocardiografía } \\
\text { intraoperatoria } \\
\triangleright \text { Complicación de cirugía } \\
\quad \text { de cadera }\end{array}$ \\
\hline Keywords \\
\hline $\begin{array}{l}\triangleright \text { Anesthetic monitoring } \\
\triangleright \text { Intraoperative } \\
\quad \text { echocardiogram } \\
\triangleright \text { Complication of hip surgery }\end{array}$ \\
\hline
\end{tabular}

Presentación del caso

Paciente de 94 años, en excelente estado general. Tuvo una caída al suelo en la que se fracturó la cadera. Su estudio clínico y por imágenes confirmó que la fractura tenía indicación quirúrgica. Entre sus antecedentes médicos destacaba diabetes mellitus e hipertensión. Tenía una cardiópata coronaria de larga evolución. A los 80 años tuvo un infarto agudo de miocardio en el que se planteó la indicación de cirugía, que fue rechazada por la familia dada la avanzada edad de la paciente, por lo que se decidió terapia médica que ella siguió de manera rigurosa.

La decisión de intervenir la cadera a esta paciente se basó en mantener la calidad de vida que ella tenía antes de la caída, asumiendo los riesgos que pudiera presentarse en el periodo perioperatorio. No operar implicaría dejarla postrada con dolor y alto riesgo de complicaciones asociadas a la inmovilidad, como escaras, enfermedad venosa profunda o diversas infecciones.

A su llegada a quirófano se monitorizó de manera no invasiva, se instaló una línea arterial y un catéter venoso central. La anestesióloga optó por una anestesia general basada en opioides y halogenados. Dados sus antecedentes y el riesgo de inestabilidad de su estado hemodinámico, también se le instaló una sonda de ecocardiografía transesofágica (ETE).

El procedimiento comenzó sin incidentes, pero a la hora de haber iniciado la cirugía presentó hipotensión severa, bradicardia y caída en la saturación de oxígeno sin cambios relevantes en el ECG. En ese momento se barajó un abanico de po- sibilidades, tales como presencia de una nueva isquemia miocárdica, hipovolemia o embolia. La ecocardiografía fue de extrema calidad (Vídeo 1 y Vídeo 2), ya que permitió diagnosticar un tromboembolismo pulmonar masivo ${ }^{(1-4)}$.

Se manejó a la paciente con soporte inotrópico basado en noradrenalina y milrinona. Al término de su cirugía fue trasladada a la unidad de cuidados intensivos, donde se inició anticoagulación con heparina transcurridas 6 horas postoperatorias. Tras un postoperatorio tórpido y de difícil manejo y de 35 días de hospitalización fue dada de alta a su casa en buen estado clínico, lúcida, orientada y autovalente.

\section{Estudio por imagen}

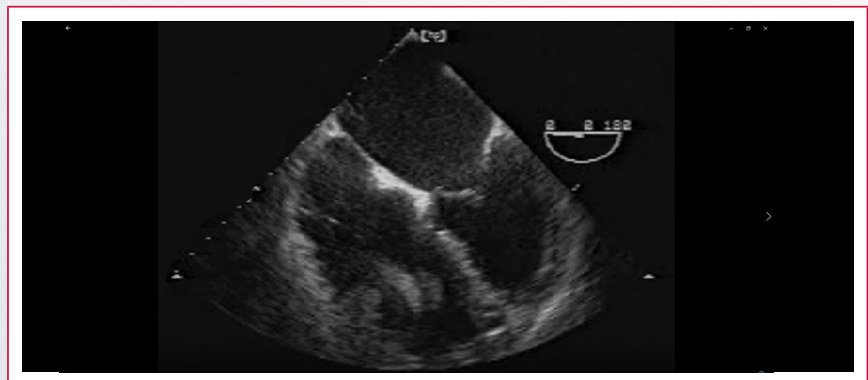

Vídeo 1. Estudio ETE a 0 ${ }^{\circ}$. Masa muy evidente en cavidades derechas 


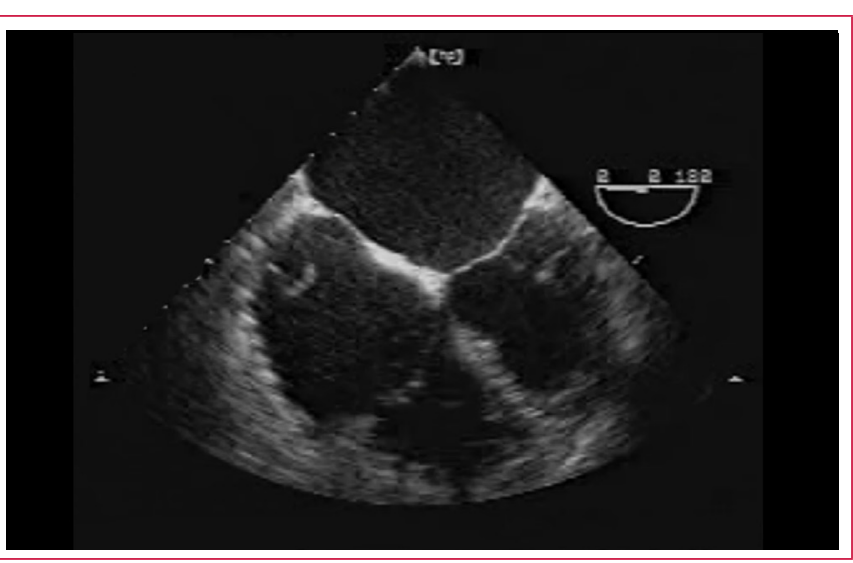

Vídeo 2. Estudio ETE a 0. Nueva imagen de la masa. El aspecto alargado corresponde a un trombo venoso que ha migrado a cavidades derechas y está en tránsito hacia el pulmón. Esta imagen hace muy evidente el diagnóstico de TEP

\section{Discusión}

Lo primero que debe plantearse en este caso clínico es pensar en la misma situación sin haber tenido disponible la ETE. En esta paciente con antecedentes clínicos significativos de cardiopatía coronaria, diabética e hipertensa que presenta un estado de shock intraoperatorio probablemente estando "a ciegas" se hubiese indicado volumen y vasopresores. Ahora bien cuando no está indicado el volumen, puede ser bastante deletéreo, como ya está ampliamente avalado en la literatura.
Como diagnóstico principal seguramente se hubiese sospechado isquemia intraoperatoria, lo que hubiese determinado un manejo perioperatorio completamente diferente, incluida una coronariografía. Sin embargo, contando con una ETE, se realizó el diagnóstico durante el evento y se manejó de acuerdo al protocolo de embolia intraoperatoria, lo que sin duda cambió su pronóstico.

\section{Ideas para recordar}

- La ecocardiografía intraoperatoria permite diagnósticos certeros en pacientes complejos, como son los ancianos portadores de múltiples patologías.

- Contar con una herramienta que permita determinar la etiología del compromiso del shock facilita su manejo.

- La ETE intraoperatoria permite el diagnóstico rápido de muchas complicaciones de la cirugía ¿Para qué aventurar diagnósticos y manejar pacientes a ciegas?

\section{Bibliografía}

1. Desciak MC, Martin DE. Perioperative pulmonary embolism: diagnosis and anesthetic management. Journal of Clinical Anesthesia 2011; 23: 153-165.

2. Ruohoniemi DM, Sista AK, Doany CF, Heerdt PM. Perioperative pulmonary thromboembolism: Current concepts and treatment options. Current Opinion in Anaesthesiology 2018; 31: 75-82.

3. Shernan SK, Schwartz AJ, Wald SH. Utility of perioperative transesophageal echocardiography in non-cardiac surgery. Refresher Courses in Anesthesiology Podcasts- American Society of Anesthesiologist, 2016.

4. Rosenberger P, Shernan SK, Body SC, Eltzschig HK. Utility of intraoperative transesophageal echocardiography for diagnosis of pulmonary embolism. Anesthesia \& Analgesia 2004; 99: 12-16. 